\title{
Nina Rodrigues e os malês
}

\author{
Hilton Costa $^{1}$
}

\section{Introdução}

O breve artigo que se segue diz respeito a uma análise de parte da obra do autor maranhense Raymundo Nina Rodrigues, desenvolvida no Programa Especial de Treinamento (PET) do curso de história da Universidade Federal do Paraná ${ }^{2}$. Me disponho a tratar da discussão proposta, por este autor, a respeito dos escravos islamizados presentes na Bahia no século dezenove. Essa observação feita a respeito dos malês é localizada principalmente na primeira metade do século dezenove, período em que os escravos islamizados realizaram uma atuação bastante destacada na sociedade baiana do período. Destacada porque na primeira metade daquele século, os malês tiveram importante participação em movimentos de "rebeldia", mais especificamente, de insurreições populares. Com essa participação os malês ganharam relativo destaque nos estudos sobre as populações africanas no Brasil.

A opção por este autor se dá porque Nina Rodrigues, que produz sua obra na segunda metade do século dezenove, é um dos primeiros estudiosos brasileiros a demonstrar um preocupação com o estudo do elemento africano presente naquela sociedade. Seu nome tornou-se, assim, uma espécie de referência básica para uma série de estudos posteriores.

O que nele chamou-nos a atenção, foram suas posições a respeito dos malês, e o fato mesmo de ter-se decidido a estudá-los. Assim procuramos, no texto que segue, localizar o período em que este autor produz seu texto sobre o assunto mencionado. A partir desta localização procuraremos entender por que e como ele constrói suas posições a respeito dos cativos islamizados. Tentaremos entender por que a imagem, dos malês ou da história dos malês, é construída de uma maneira relativamente diferente, pelo autor, das imagens dos demais escravos que vieram ao Brasil.

Em um primeiro momento observaremos então o contexto no qual a obra é produzida: o Brasil e o mundo, no que diz respeito às principais correntes de pensamento que acabam por influenciar o autor em questão. A partir daí, buscaremos analisar suas posições sobre os malês. Em um momento posterior, seguirá uma análise comparativa dos textos deste autor citados, com os de autores mais recentes, ou seja, observaremos o texto do final do século

\footnotetext{
${ }^{1}$ Graduação - História/UFPR (PET-SESu).

${ }^{2}$ A versão que aqui se segue é levemente modificada, da apresentada no Programa Especial de Treinamento, PET, curso de história da Universidade Federal do Paraná.
} 
dezenove e inicio do século vinte, no caso de Nina Rodrigues, comparando-o com autores mais recentes. Assim, mapearemos as mudanças no trato da temática em questão - devido a mudanças no meio cientifico.

Porém, mesmo com as mudanças ocorridas em quase um século de intervalo existente entre os escritos de Nina Rodrigues e os de João José Reis, mantêm-se muito dos mesmo eixos de análise. A curiosidade sobre a especificidade destes cativos permanece. Seja por sua particularidade religiosa, étnica ou por sua "rebeldia". Estes então serão os temas a serem abordados neste artigo, com o qual pretendemos começar uma discussão em torno de alguns autores da historiografia brasileira que se mostram em boa medida preocupados com a formação de nossa identidade nacional.

Trata-se do caso de Nina Rodrigues, um dos primeiros autores nacionais a pensarem a questão da nacionalidade, e do brasileiro em si, a partir da análise dos povos africanos e de origem africana presentes no Brasil. Rompe, então, com um silêncio que se mantinha dentro das análises a respeito do Brasil, nas quais essa temática raramente era analisada de forma sistemática.

\section{A sociedade brasileira à época de Nina Rodrigues}

A produção de Nina Rodrigues situa-se nos últimos vinte cinco anos do século dezenove. Este período é bastante movimentado; a escravidão chega ao fim de uma maneira oficial ${ }^{3}$, dá-se o fim do Império do Brasil e institui-se a República do Brasil ${ }^{4}$, para citarmos apenas alguns fatos fundamentais na reestruturação da sociedade brasileira. As novas relações sociais estabelecidas no Brasil, com destaque à implantação do trabalho livre, traz ao cenário da historia novos atores: ex-escravos e mestiços passam a compor categorias que se faz necessário registrar e mesmo estudar.

A omissão em relação a estas camadas sociais, perpetrada até então, começa a desfazer-se ${ }^{5}$. Assim, apresentam-se neste momento estudiosos nativos dispostos a observar este segmento da sociedade. Pois existe o desejo, por parte de uma elite nacional, de se formar, nos trópicos, uma nação sob moldes europeus. O que resultaria difícil, devido à presença de duas categorias de indivíduos já mencionadas - negros e mestiços. A formação de um país em moldes europeus apoiar-se-ia em uma população de maioria branca, o que não correspondia à realidade do pais. Mais ocorrente era o inverso.

No entanto, a presença do elemento negro não era um impecilho para o implante deste projeto de sociedade - o exemplo dos Estados Unidos da

\footnotetext{
${ }^{3}$ A Lei Áurea de 1888 decreta de forma oficial o fim da escravidão no Brasil.

${ }^{4} \mathrm{O}$ Marechal Deodoro da Fonseca proclama a república em 1889.

${ }^{5}$ Citamos por exemplo a história do Brasil escrita por Varnhagem, onde o elemento negro é omitido da história brasileira.
} 
América estava posto para solucionar esta questão. Porém, este "modelo estadunidense" não responde a uma questão básica em se tratando de formação de sociedade brasileira. Trata-se da questão do mestiço, categoria determinante no contexto brasileiro. Além disso, não havia no Brasil uma maioria branca como nos Estados Unidos.

Esta exposição foi realizada para demonstrar em linhas gerais como se encontrava a sociedade brasileira à época da produção intelectual destes autores. Nesse sentido, também achamos pertinente oferecer uma visão, mesmo que panorâmica, da situação da disciplina histórica no Brasil do período.

Que tipo de história se pretendia construir aqui ? O marco mais importante neste sentido, ou pelo menos um dos mais importantes, foi a criação do IHGB, Instituto Histórico e Geográfico Brasileiro ${ }^{6}$; além dos demais Institutos regionais; eles são de certa forma fundamentais no processo de criação da disciplina histórica no Brasil.

Também é marca da historiografia brasileira do período o positivismo $^{7}$, o determinismo geográfico ${ }^{8}$, o cientificismo ${ }^{9}$ e a influência das demais ciências no pensamento histórico. Não que isso seja exclusividade deste período; mas para entendermos muito do que o autores por nós citados afirmam temos de estar cientes de tais especificidades.

Por fim, podemos colocar que durante os setenta e cinco anos finais do século XIX a elite letrada brasileira, - originada da independência (7 de setembro de 1822) - , vê-se obrigada a começar a pensar o que é o Brasil e, principalmente, quem é o brasileiro. Ou seja, uma discussão sobre a nacionalidade brasileira e sobre sua formação. Esses dados, assim como os já citados, são muito importantes para a compreensão do autor em questão.

\section{As doutrinas estrangeiras}

A pouco mencionamos, de forma resumida, como se encontrava a sociedade brasileira à época em que Nina escreve, passando rapidamente sobre de que maneira estava montado campo letrado nacional do período. Entretanto, não podemos perder de vista que uma parte considerável dauquels letrados brasileiros concluíam, ou faziam parte dos seu estudos, na Europa. O que nos leva a observar quais correntes de pensamento se faziam presentes no Velho Mundo quando Nina escreve.

\footnotetext{
${ }^{6} \mathrm{O}$ IHGB foi fundado em 1838.

${ }^{7}$ Doutrina de pensamento fundada por Augusto Comte bastante influente no Brasil, da virada do século dezenove para o vinte.

${ }^{8}$ Corrente de pensamento que defendia que o posicionamento geográfico era o fator determinante para o desenvolvimento de um povo, ou de uma nação.

${ }^{9}$ Forma de pensamento muito difundida no século dezenove, segundo a qual tudo deveria possuir uma explicação cientifica, o que produziu uma espécie de culto à ciência.
} 
Entretanto, este autor constitui uma espécie quase que geral de exceção à regra citada acima - Nina só desloca-se para lá depois de ter concluído seus estudos. De qualquer forma, seus referenciais teóricos são oriundos da Europa, em especial da França - o grande ponto de referência da intelectualidade brasileira da época. É preciso frisar, contudo, a existência de correntes minoritárias mais próximas do pensamento estadunidense; destacamse aqui autores como Alberto Torres e Manuel Bonfim.

As influências de Nina Rodrigues são o determinismo social e o evolucionismo, doutrinas de intelectuais baseadas não só nos aspectos culturais dos povos, mas em muito na biologia. Esse racialismo que de certa forma age em conjunto com o evolucionismo e o determinismo defende a idéia do conjunto predominando sobre o indivíduo. A sociedade define o sujeito, determinismo cultural, a raça dita a capacidade de crescimento do indivíduo. Essas doutrinas buscam, como já dito, fundamentação na biologia constituindo o que veio a ser conhecido como racismo cientifico.

Esse tipo de pensamento sempre foi aceito com relativas ressalvas, não em sua plenitude, pela elite letrada brasileira. Nina Rodrigues é quem mais aceita estas teorias, como nos fala Thomas E. Skidmore: Na aceitação das teorias racistas estrangeiras, Nina Rodrigues fora mais longe que a maior parte da elite brasileira. ${ }^{10}$ Contudo, mesmo sendo um adepto do chamado racismo cientifico Nina também apresenta ambigüidades ao estudar a situação do negro no Brasil - como boa parte da elite brasileira - pois para ele a presença negra era prejudicial à composição da nação. Mas o pior era a presença do mestiço. Pois, ao mesmo tempo em que o autor era um defensor da inferioridade cientifica dos povos de cor, ele também acreditava na evolução desses mesmos povos.

Uma evolução que poderia se dar se houvesse um crescimento em separado, e obviamente com a tutela da raça branca, a mais evoluída. Ficam frequentemente subentendidas, e por vezes explícitas, alusões ao modelo estadunidense de separação das raças.

Os principais nomes do pensamento esrtangeiro que em muito influenciou a intelectualidade brasileira são os de Gobineau, Renan, Taine, Buckle entre outros, que, de certa forma, dão corpo ao racismo cientifico, ao determinismo social e cultural, em suma, ao evolucionismo ${ }^{11}$. Nestas questões e que Nina Rodrigues fundamenta muito daquilo que propõe.

\footnotetext{
${ }^{10}$ SKIDMORE, Thomas E.. Preto no Branco. p. 77.

11 Essas teorias européias sobre o racialismo estão discutidas e apresentadas de forma bastante interessante no texto de Tzvetan Todorov, Nós e outros, 1993, principalmente em relação ao pensamento francês.
}

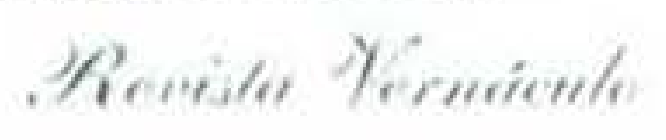




\section{Os malês segundo Nina Rodrigues}

A religiosidade é um ponto central na análise dos malês, segundo diversos enfoques; em Nina a questão aparece de forma destacada, e advém dela muito das conclusões do autor a respeito dos malês. A questão religiosa é fator determinante nas análises sobres os movimentos dos quais eles participaram, e isso se faz presente na análise de Nina:

(...)A insurreição de 1835, cuja história completa compulsamos, em detido exame, nos autos dos processos-crimes a que deu lugar, põe em forte destaque a influência do islamismo nos negros brasileiros, ao mesmo tempo que descobre os intuitos religiosos de toda esta série de levantes escravos na Bahia.(... $)^{12}$

Como podemos observar claramente, o dado religioso é relevante para a análise de Raymundo Nina Rodrigues. Entretanto, ele se mostra ciente da complexidade de seu objeto de estudo, chamando a atenção para o fato de que outros aspectos também se mostravam importantes para o estudo dos malês. Dentre esses outros elementos por nós citados aparece um que nos chama em demasia a atenção: trata-se da preocupação do autor com a formação da identidade nacional brasileira. E ao observamos o seu texto por esse viés, podemos notar vários traços de sua formação intelectual, baseada no contexto que citamos a pouco, e principalmente a posição ambígüa que assume ao tratar o tema.

A religião como foco central, ou como um dos principais focos de origem dos movimentos dos quais participaram os malês, é vista na análise de Nina não como uma prova de fanatismo religioso, de barbárie. Trata-se do inverso: a prática do islamismo pelos negros, segundo as observações de Nina, pode ser notada como um sinal não de barbárie, mas de civilidade. Enquanto adepto do evolucionismo o autor nota, nessa aceitação do islamismo pelos negros, uma evolução. Ou seja, a aceitação de uma religião superior, mais evoluída, requeriria uma capacidade intelectual maior. Estes negros seriam então, mais evoluídos que os animistas fetichistas ${ }^{13}$. Estes sim, os representantes da barbárie.

\section{Os malês e a formação nacional}

Assim, os malês ganham destaque dentro da perspectiva do autor, não só por seu envolvimento nos movimentos insurrecionais do inicio do século dezenove, mas também por sua origem. Pertenciam ao grupo africano que o

\footnotetext{
${ }^{12}$ RODRIGUES, Raymundo Nina. Os Africanos no Brasil, p. 53.

${ }^{13}$ Nina Rodrigues analisa os costumes animistas e fetichistas dos negros, no Brasil, usando com referência os baianos em outro trabalho seu intitulado "O animismo fetichista dos negros baianos" 
autor define como sudanês: "Dentre estes, (os negros trazidos ao Brasil) se não a numérica, pelo menos a preeminência intelectual e social coube sem contestação aos negros sudaneses" 14

Assim, os malês, de Nina Rodrigues não seriam os africanos mais "atrasados", fanáticos, como deixam transparecer alguns apontamentos, como por exemplo os do missionário Etiene Brazil ${ }^{15}$. Eles seriam o inverso, os mais adiantados. Quanto às reflexões sobre a formação da nacionalidade brasileira realizadas pelo autor, elas possuem um viés evolucionista. Valendo-se em boa medida de um modelo estadunidense, ou anglo-saxão, de segregação das raças, o autor acredita no processo de evolução das raças humanas, como podemos notar na citação que ele utiliza de Abel Hovelacque: "Os negros africanos são o que são; nem melhores, nem piores do que os brancos; pertencem apenas a uma outra fase de desenvolvimento intelectual e moral". ${ }^{16}$

Seguindo por esta linha de raciocínio, poderemos perceber que Nina, através do estabelecimento de uma escala universal de valores, conclui que o grupo sudanês seria o mais evoluído dentre os povos africanos.

Cabe dizer também que nessa escala evolutiva, a raça branca estaria no estágio mais alto, e teria então o direito ou o dever de civilizar as outras; sem perguntá-las se desejavam ser civilizadas, como prega "o manual" do neocolonialismo europeu do século dezenove.

No entanto, há em Nina, ao mesmo tempo, uma crença de que as raças humanas poderiam evoluir por si sós, desde que separadas - no sentido de se evitar a miscegenação. Por essas posições é que ele condena a escravidão, pois esta instituição além de impedir a evolução da raça negra, prejudicaria a branca, já que favorecia a miscegenação. Por consequiência, o mestiço é um elemento caro a Nina Rodrigues; seria ele o "culpado" pelo atraso brasileiro:

Em trono deste fulcro - mestiçamento -, gravita o desenvolvimento da nossa capacidade cultural e no sangue negro havemos de buscar, como em fonte matriz, com algumas das nossas virtudes, muito dos nossos defeitos. ${ }^{17}$

Para ele, a nossa nacionalidade construiu-se em cima deste dois elementos: o negro e os mestiços; o que marcaria a nação brasileira negativamente. Se eles não fossem impedidos de evoluir, seja pela escravidão, seja pela miscegenação, poderiam alcançar a civilidade. E de forma mais rápida

\footnotetext{
${ }^{14}$ RODRIGUES, Raymundo Nina. Os africanos no Brasil. p. 37

${ }^{15}$ Missionário católico francês radicado no Brasil que faz um relato sobre a insurreição malê de 1835, taxando os insurretos de fanáticos e bárbaros. Seu relato está na Revista do [HGB, vol. 72 n. ${ }^{\circ}$ 2, p. 69-126.

${ }^{16}$ HOVELACQUE, Abel. Les Nègres de l'Afrique sous-équatoriale. Paris, 1889. P. 458. In: RODRIGUES, Raymundo Nina. Os Africano no Brasil. p. 5

${ }^{17}$ RODRIGUES, Raymundo Nina. Os africanos no Brasil, p. 14
}

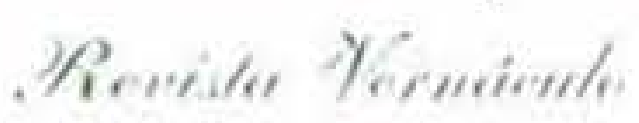


que os outros povos, como já demonstrava sua aceitação de uma religião superior.

E seguindo a idéia já exposta de um crescimento em separado, o modelo "estadunidense", eles poderiam contribuir para a construção de um país mais evoluído, nos moldes dos Estados Unidos.

\title{
V. i. A complexidade da formação da nacionalidade brasileira
}

Nina Rodrigues destaca os malês como os africanos mais evoluídos presentes no Brasil, e aponta sua preeminência intelectual perante os outros africanos e mesmo sobre os mestiços. Como já apontado neste trabalho, ao analisar os malês ele deixa fluir algumas de suas preocupações a respeito da formação da nacionalidade brasileira, caminhando para uma complexidade maior. $\mathrm{O}$ autor demonstra preocupação com o processo evolutivo do povo brasileiro, que estaria marcado pelo atraso desde sua origem na colonização portuguesa.

Ao mesmo tempo em que critica os portugueses, ele os defende no que diz respeito à especificidade brasileira, ressaltando que o mínimo de civilidade e urbanidade presentes na formação do Brasil são oriundas de Portugal:

\begin{abstract}
$\mathrm{Na}$ primeira alternativa, a nossa doentia preocupação de discutir as questōes de principio, se complica efetivamente, no caso particular de uma nota curiosa de psicologia de povo compósito. Há flagrante injustiça no zelo de que pomos em defender os foros da nossa linhagem. Desabrida a intolerância com os portugueses. Não há quem não se julga autorizado a deprecia-los, a deprimi-los. Como que pesa e envergonha o sangue português que nos corre nas veias e a cada passo, por vezes sem noção da mais elementar urbanidade, clamamos que a nossa decadência provém da incapacidade cultural dos lusitanos, da baixa estirpe dos degradados, galés e prostitutas mandados para colonizar o país. E ninguém aí descobre todavia uma parte de ofensa pessoal que the possa caber.
\end{abstract}

Podemos notar neste ponto que a preocupação do autor não está somente no elemento negro e mestiço presentes na formação da nacionalidade brasileira. Ele procura demonstrar uma complexidade maior para a situação da seguinte forma: os portugueses não são, no caso brasileiro, sinônimo de atraso, mais sim o inverso. Principalmente se contrapostos aos outros grupos presentes no Brasil, como indígenas, negros e mestiços.

Como já foi dito, os sudaneses seriam os mais evoluídos dentre os negros trazidos ao Brasil. Entretanto, não constituíam a maioria dos grupos para cá trazidos. Esse dado também influiria no atraso do Brasil enquanto nação, o que introduz mais uma marca importante do pensamento deste autor: o determinismo social. Dois grupos importantes na formação da nacionalidade

\footnotetext{
${ }^{18}$ Idem p. 1-2.
} 
em questão não eram os ideais: os brancos eram lusos na sua maioria e os negros, os mais "atrasados". O mestiço era o terceiro, um degenerado por natureza $^{19}$. O que leva-nos a considerar a visão do autor fatalista em relação ao país, como está expressado neste trecho:

A raça negra no Brasil, por maiores que tenham sido os seus incontestáveis serviços à nossa civilização, por mais justificadas que sejam as simpatias de que a cercou o revoltante abuso da escravidão, por maiores que se revelem os generosos exageros dos seus turiferários, há de constituir sempre um dos fatores da nossa inferioridade como povo. ${ }^{20}$

Ali está presente uma descrença no futuro do Brasil, em comparação à Europa e aos Estados Unidos. O Brasil teria uma marca de origem - o atraso devido à constituição de sua população (principalmente no que diz respeito à miscigenação). Por sua não-miscigenação, os Estados Unidos seriam mais evoluídos.

Então podemos notar que a presença negra no Brasil poderia ser "melhor" se não tivesse havido a miscegenação e se tivessem sido trazidos ao Brasil negros de grupos mais evoluídos, como os sudaneses, em maior quantidade.

\section{A análise dos malês recentemente}

Atualmente, os malês continuam tendo um espaço destacado dentro dos estudos sobre a presença africana no Brasil. Sua revolta de 1835, como evento histórico, muito provavelmente só perde em espaço, dentro dos estudos afro-brasileiros, para Palmares.

Assim, observando algumas análises mais recentes sobre os malês e seu movimento insurrecional, podemos notar mudanças importantes no tratamento aplicado a esta categoria de escravos, mudanças estas que o tempo, e novas pesquisas, proporcionaram. Porém, ao mesmo tempo que podemos notar as mudanças no trato desta temática, pela historiografia, também verificase algumas permanências interessantes que demonstram que os estudos promovidos por Raymundo Nina Rodrigues, na virada do século dezenove para o século XX, foram feitos de uma maneira sistemática e aprofundada. O que não se verificava em estudos sobres as populações de cor em sua época.

A primeira mudança significativa no trato ou na abordagem a respeito dos malês, bem como dos demais povos não brancos, originou-se não na área

\footnotetext{
${ }^{19}$ É interessante perceber que o elemento indígena tem pouco espaço dentro dos textos de Nina Rodrigues observados para realização deste trabalho. Nota-se entretanto, que este elemento aparece como que diluído no conceito de mestiço por ele apresentado.
}

${ }^{20}$ RODRIGUES, Raymundo Nina. Os africanos no Brasil. p. 7. 
das ciências humanas, mas sim na biologia. Com o surgimento e o desenvolvimento da genética, muitos dos argumentos científicos racistas caem por terra. A origem comum da humanidade, que a genética vem demonstrar, quebra uma das espinhas dorsais do racismo cientifico que é sua base biológica. Assim, só resta o racismo culturalmente justificado para se defender a suposta inferioridade dos povos de cor.

Essas mudanças são significativas dentro da análise dos malês. É importante levar-se em conta que quando Nina realiza seus estudos não dispõe destas informações. As análises mais recentes procuram, por exemplo, observar a extensão de sua revolta, que na análise de Etienne Brazil, e um pouco na de Nina, é uma espécie de Jihad islâmica contra o catolicismo brasileiro. E em João José Reis aparece como um movimento significativo mas de uma extensão um pouco mais reduzida, ou mesmo de pouca significância, como aponta Stuart B. Schwartz :

O último levante escravo ocorreu em 1835, quando africanos muçulmanos de Salvador, a maioria nagôs, mas incluindo alguns haussás, jejes e tapas, atacaram instalaçōes e policiais e militares e por dois dias empreenderam uma guerra na cidade. (...) A extensâo dessa rebelião e seus aspectos islâmicos geraram curiosidade e interesse pela "grande insurreição". Para nossos propósitos, porém ela foi simplesmente a última de uma longa série de revoltas que marcaram a passagem da sociedade escravista baiana ao século $\mathrm{XIX}^{21}$

Mas a contestação sobre a extensão do movimento dos malês abre outros caminhos, como o de se observar que tipo de escravos eram os malês, que tipo de islamismo eles praticavam, enfim, o assunto desdobra-se e complexifica-se. Mesmo as motivações que, em boa medida, levaram Nina a destacar os malês não se justificam mais atualmente - principalmente no que diz respeito a seu sentido evolucionista - outros aspectos continuam a despertar curiosidade como apresentado brevemente à pouco.

$\mathrm{O}$ argumento de que a religião seria o ponto central dos movimentos insurrecionais protagonizados pelos malês, continua em discussão. Entretanto, é quase consenso que a solidariedade religiosa é uma das espinhas dorsais desses movimentos, em especial o de 1835 . Em um livro e um artigo ${ }^{22}$ publicados na década de oitenta do século vinte, por João José Reis, que constituem um material de peso para a análise do assunto, a solidariedade religiosa dos escravos islâmicos ainda é apresentada como algo fundamental, mas que não foi a única razão daqueles movimentos. Ou seja, a religião tem um papel importante mas não seria o único fator de peso a motivá-los.

${ }^{21}$ SCHWARTZ, Stuart B. Segredos Internos. p. 392.

${ }^{22}$ O livro publicado em 1986 chama-se Rebeliāo Escrava, a história do levante dos malês 1835 , e o artigo publicado em 1988 chama-se localizado em coletânea denominada Escravidão e Invenção da Liberdade. 
O estudo João J. Reis vai para um caminho que busca demonstrar que, mais do que movimentos religiosos, as insurreições protagonizadas pelos malês eram também movimentos sociais. Que mais do que questionar a ordem religiosa vigente, questionavam a ordem social escravista. A idéia da Jihad promovida pelo islão baiano é descartada. E isso muito se justifica pela especificidade do islamismo praticado pelos malês baianos, que segundo artigo de Rosemarie Quiring-Zoche ${ }^{23}$ era demasiado rudimentar, devido à própria situação social de seus membros - em boa parte cativos.

A autora mencionada fundamenta suas afirmações em um relato de um viajante islâmico, que passara pela Bahia na segunda metade do século dezenove. Por ser instruído na religião maometana, ele teria sido procurado por malês. Essa é uma hipótese bastante provável, se notarmos os objetos e as notas sobre os autos de devassa provenientes desses movimentos, presentes tanto no texto de Nina Rodrigues como no de João José Reis; o que evidencia a precariedade do islamismo dos malês. Porém, mesmo se constituindo em uma forma rudimentar de islamismo, se assim podemos denominá-lo, ele foi muito importante na organização dos movimentos malês.

Assim notamos que análises recentes preocupam-se com aspectos da ordem da extensão dos movimentos, se eram religiosos ou sociais. O professor Reis caminha na direção de localizar estes movimentos como sociais, mas com fortes aspectos religiosos. Esta última constitui-se como a tendência mais forte de análise a respeito dos malês hoje em dia.

Mas, sem dúvida, o que mais chama atenção em relação à análise de Raymundo Nina Rodrigues e as mais atuais, é que apesar dos autores recentes também preocuparem-se com a procedência dos cativos islâmicos, eles o fazem por motivos bastante diversos. Nina queria estes dados para perceber se os cativos procediam de localidades ocupadas por segmentos mais "evoluídos" dos povos africanos. Enquanto que, mais recentemente, tal preocupação se mostra mais relacionada com a idéia de como os malês teriam chego ao islamismo, por exemplo, ou como o culto se organizava em África e depois no Brasil. Mesmo porque o ideal evolucionista de Nina já não cabe mais.

No entanto, se ignorarmos este último aspecto, muito do trabalho de Nina continua de acordo com as novas perspectivas a respeito do assunto. Por exemplo, podemos colocar que mesmo que a religiosidade seja a peça-chave para Nina, ele nunca refutou os aspectos sociais dos movimentos malês, ainda que estes aparecessem timidamente.

${ }^{23}$ Artigo publicado na Revista Afro-Ásia número 19-20, 1997

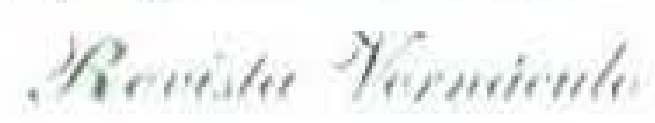




\section{Considerações Finais}

Nascido em quatro de dezembro de 1862, na cidade de Vargem Grande, localizada na então Província do Maranhão; filho de Dona Luísa Rosa Nina Rodrigues e do Coronel Francisco Solano Rodrigues, Raymundo Nina Rodrigues começa seus estudos em sua cidade natal. Faz o curso primário em São Luís, capital da Província do Maranhão, cursa o Colégio São Paulo, completando essa primeira etapa de seus estudos no Seminário das Mercês. Ruma posteriormente para Salvador, em 1882, com o intuito de estudar medicina, e o faz até o quinto ano. Transfere-se então para o Rio de Janeiro, em 1886, vindo a diplomar-se em medicina, em 1887. Em 1888 retorna ao norte do país fixando-se em Salvador, onde passa a lecionar na Faculdade de Medicina da Bahia. Falece em 17 de julho de 1906 em Paris, França. ${ }^{24}$

Esta é uma breve biografia do autor que procuramos observar, especialmente no que diz respeito a sua análise dos malês, ou "negros maometanos" como ele próprio os denomina. Como buscamos demonstrar ao longo deste artigo, este autor praticamente inaugura um campo de trabalho: o estudo sistemático dos africanos presentes no Brasil, e dos afro-brasileiros. Nesse sentido, Thomas E. Skidmore aponta: $O$ primeiro estudo etnográfico sério e respeitável do afro-brasileiro por um brasileiro não proveio dos museus, mas de um professor de medicina originário da prestigiosa faculdade da Bahia ${ }^{25}$.

A formação acadêmica de Nina é bastante interessante, no sentido de que a medicina, mais perto da biologia, procurava compreender a diferença ou as diferenças entre as raças, seja pelo tamanho do crânio ou da forma física. À época de Nina, tal tipo de investigação era corrente; e visava a explicar o indivíduo pelo grupo a que pertencia. Um campo marcado pelo evolucionismo, tão presente nos escritos de Nina, como nos estudos de outros autores da época. A biologia mostrava-se, então, como uma influência forte e determinante nas ciências humanas.

O evolucionismo destaca-se no pensamento de Nina de um forma bastante interessante quando ele, de certa forma, lamenta a presença diminuída de brancos no Brasil desde de sua formação, em comparação com o número de negros e mestiços. Nunca tivemos, como os Estados Unidos, um excedente respeitável de população branca(... ${ }^{26}$ Usa o único parâmetro de comparação possível, os Estados Unidos, também importadores de africanos, porém menos suscetíveis à miscegenação.

\footnotetext{
${ }^{24}$ Informações contidas em apêndice realizado por Fernando Sales presente em Os Africanos no Brasil edição da coleção Brasiliana.

${ }^{25}$ SKIDMORE, Thomas E.. Preto no Branco, p. 74.

${ }^{26}$ RODRIGUES, Raymundo Nina. Os africanos no Brasil, p. 5 
A condição da raça negra na América Latina é completamente diversa da situação que ela se encontra nos Estados Unidos da América do Norte. Sitiada pela raça branca, que se abstém, quanto pode, de se cruzar com ela, a raça negra concentra-se e isola-se no Black Bell do sul e centro da grande federação norte-americana (...) na América latina, em particular no Brasil, a raça negra, predominando muitas vezes pela superioridade numérica, incorporou-se à população local no mais amplo mestiçamento. ${ }^{27}$

Este dado pode muito bem explicar a preocupação de Nina com a possibilidade do surgimento de dois "brasis": um predominantemente branco e mais evoluído, no sul, devido à imigração européia; e outro negro, mestiço, ocupando o restante de um território fadado ao atraso.

Ao brasileiro, mais descuidado e imprevidente não pode deixar de impressionar a possibilidade da oposição futura, que já se deixa entrever, entre uma nação branca, forte e poderosa, provavelmente de origem teutônica nos estados do Sul, donde o clima e a civilização eliminarão a raça negra, ou a submeterão, de um lado; de outro lado, os estados do Norte, mestiços, vegetando na turbulência estéril de uma inteligência viva pronta, mas associada à mais decidida inércia e indolência, ao desânimo e por vezes à subserviência, e, assim, ameaçados de se converterem em pasto submisso de todas as explorações de régulos e pequenos ditadores. ${ }^{28}$

A aceitação desse tipo de pensamento por um brasileiro, que haveria de construir uma visão bastante pessimista com relação ao futuro país, não é um fato isolado: o fascínio brasileiro pela sociedade francesa, freqüente no período, se dava em vários sentidos. Um desses sentidos é o de compartilhar muitas idéias do pensamento francês, este último uma das raízes do pensamento racista cientifico ${ }^{29}$. Tal afinidade facilitava a entrada destes autores no meio letrado brasileiro. Podemos crer que a busca de uma sociedade européia nos trópicos era objetivo da elite brasileira, porém, como a especificidade do Brasil estava no fato de que este possuía um contigente muito grande de negros, o único modelo de país desenvolvido com esta característica eram os Estados Unidos, como vimos a pouco.

Entretanto, mesmo este modelo não responde à especificidade brasileira devido à falta do mestiço, elemento fundamental em nossa formação. Mesmo assim, Nina nota na sociedade estadunidense um bom caminho, como já citado neste trabalho: a idéia de um crescimento em separado das raças. E se essas raças fossem já mais evoluídas desde de seu ponto de partida, neste caso a África, tudo seria mais facilitado. Nina possui uma particularidade dentro do

\section{${ }^{27}$ RODRIGUES, Raymundo Nina, Os Africanos no Brasil, p. 13}

${ }^{28}$ Idem. p. 8-9 cabendo ainda colocar que neste trecho o autor faz uso de um correspondente em Santa Catarina, que afirmava o pouco desenvolvimento das crianças negras na região, nota 4 página 8

${ }^{29}$ Como podemos observar na obra "Nós e os Outros" de Tzvetan Todorov, na qual ele analisa o pensamento racialista francês.

$$
\text { Premile Yrimionte }
$$


meio evolucionista, determinista: ele cria capacidade de civilização dos povos de cor, apesar de acreditar em sua inferioridade.

Depositamos neste ponto o destaque dado aos malês, que enquanto pertencentes ao grupo sudanês seriam melhores que outros grupos de africanos trazidos ao Brasil. Sua aceitação dos paradigmas islâmicos funciona como um exemplo desta superioridade. Eles poderiam contribuir para a construção de um país mais evoluído

Assim, buscamos demonstrar que Nina Rodrigues faz sua análise dos malês, grupo envolvido em uma série de insurreições na Bahia da primeira metade do século dezenove, de forma bastante particular. Há neste autor uma preocupação com a formação nacional brasileira. Mais do que para a problemática religiosa ou social, procuramos chamar a atenção para um outro lado que seria o da constituição da nação e da nacionalidade brasileira. Para dar conta desta problemática, Nina se encontra como um elemento até então marginal na história brasileira - o elemento negro -, residindo neste ponto, e em alguns mais que pretendemos investigar futuramente, a importância deste autor na análise da formação do povo brasileiro.

\section{Referências Bibliográficas}

1. BRAZIL, Etienne Ignace. Os Malês. Revista do Instituto Histórico e Geográfico do Brasil, vol. 72, n. ${ }^{\circ}$ 2, 1909, pp. 69-126.

3. LOPES, Nei. Bantos, Malês e Identidade Negra. Rio de Janeiro: Forense Universitária, 1988.

4. QUIRING-ZOCHE, Rosemarie. Luta Religiosa ou Luta Política? O Levante dos Malês da Bahia segundo uma fonte islâmica. In: Afro-Ásia, Revista FFHC/UFBA, n. ${ }^{\circ}$ 19-20, 1997.

5. REIS, João José. Rebelião Escrava no Brasil: a história do levante dos malês (1835). São Paulo: Editora Brasiliense, 1986.

6. REIS, João José. Escravidão e Invenção da Liberdade: estudos sobre o negro no Brasil. São Paulo: Editora Brasiliense/CNPq, 1988.

7. REIS, João José e SILVA, Eduardo. Negociação e Conflito: a resistência negra no Brasil escravista. São Paulo: Cia. das Letras, 1989.

8. RODRIGUES, Raymundo Nina. Os Africanos no Brasil. São Paulo: Cia. Editora Nacional [Brasília], Universidade de Brasília, 6. ${ }^{a}$ Ed., 1982.

9. SCHWARTZ, Stuart B. Segredos Internos: engenhos e escravidão na sociedade colonial 1550-1835. São Paulo: Cia. das Letras/CNPq, 1988.

10. SKIDMORE, Thomas E. Preto no Branco: raça e nacionalidade no pensamento brasileiro. Rio de Janeiro: Paz e Terra, 1976.

11. TODOROV, Tzvetan. Nós e Outros: a reflexão francesa sobre a diversidade humana. Vol.I. Rio de Janeiro: Jorge Zahar Editor,1993. 